\title{
Türkiye'nin Meyve ve Sebze İhracatı: Bir Çekim Modeli Uygulaması
}

\author{
The Turkey's Fruit and Vegetable Exports: An Application of the Gravity \\ Model
}

Fatih Kaplan, Mersin Üniversitesi, Türkiye, fatihkaplan@mersin.edu.tr

Öz:Bu çalışmanın amacı, Türkiye'nin meyve ve sebze ihracatını Poisson Pseudo Maksimum Olabilirlik (PPML) yöntemi ile tahmin etmektir. Bu amaç doğrultusunda 2004-2014 dönemini kapsayan ve Türkiye’nin ihracat yaptığ 63 ülkeye ait yıllık panel veriler çekim modelinde kullanılmıştır. Yapılan tahminin sonuçlarına göre, Türkiye'nin sebze ve meyve ihracatı yaptığ ülkelerin ekonomik büyüklükleri ve kişi başına düşen gelirleri, sebze ve meyve ihracatı ile pozitif ilişkiliyken, ülkelerin birbirlerine olan uzaklı̆̆ meyve ve sebze ihracatı ile negatif ilişkilidir. Ayrıca, kukla değişkenler olarak kullanılan sinır komşusu ülke olma durumu meyve ve sebze ihracatını olumlu yönde etkilerken, AB üyesi ülke olma durumu, 2008 küresel finansal krizi ve 2010 Arap Baharl siyasi krizinden olumsuz yönde etkilendiği tespit edilmiştir. Sonuç olarak, politika yapıcıları meyve ve sebze ihracat stratejisinde söz konusu tespitleri dikkate almaları önem arz etmektedir.

Anahtar Sözcükler: Türkiye'nin Meyve ve Sebze ihracat, Çekim Modeli, Panel Veri

Abstract: This study aims to estimate Turkey's fruit and vegetable exports by using Poisson Pseudo-Maximum-Likelihood method (PPML). For this purpose, annual panel data which covers the period between 2004 and 2014 and belongs to 63 countries to which Turkey exports are used with gravity model. The results of estimation process shows that economic size and gross domestic per capita of the countries to which Turkey exports fruits and vegetables are positively correlated with fruit and vegetable export whereas geographical distance between countries are negatively correlated with fruit and vegetable export. Furthermore, while having a common border, which is used as a dummy variable, has a positive impact on fruit and vegetable exports, being a member of EU, 2008 global financial crisis and 2010 Arab Spring political crisis have a negative impact on fruit and vegetable exports. In conclusion, the policy makers should take into account the aforesaid findings in Turkey's fruit and vegetable export strategy.

Keywords: Turkey's Fruit and vegetable Exports, Gravity Model, Panel Data

\section{Giriş}

Meyve ve sebze üretimi, tarım ürünleri sektöründe ekonomik anlamda oldukça önemli bir yere sahiptir. Meyve ve sebze üretiminde birim alandan elde edilen gelir, diğer tarım ürün gruplarına göre daha fazla olmasından dolayı ülke ekonomilerine diğer tarım ürünlerine oranla daha fazla katkı sağlamaktadır. Ayrıca, meyve ve sebze üretimi bir yandan sanayiye hammadde girdisi sağlarken diğer yandan da ihracat yoluyla ülkeye döviz kazandırmaktadır. Bu nedenlerle son yıllarda meyve ve sebze sektörüne yönelik yapılan akademik çalışmalar hızla artmaktadır.

Türkiye sahip olduğu iklim ve toprak özellikleriyle meyve ve sebze üretimine oldukça uygun bir ülkedir. Dünyada üretimi yapılan 150'ye yakın meyve ve sebze türünün yarıdan fazlası Türkiye'de ekonomik olarak üretilebilmektedir. Uygun iklim ve topoğrafik yapısı nedeniyle Türkiye'de birçok meyve ve sebze çeşidi, hemen hemen her mevsimde ve birçok farklı bölgede yetiştirilebilmektedir. Bu özellikleriyle Türkiye meyve ve sebze üretiminde ve ihracatında diğer ülkeler karşısında oldukça avantajlı bir konuma sahiptir. Bu avantajlı konumuna rağmen, üretiminin büyük bir çoğunluğu farklı sebeplerden dolayı dış ticarete kanalize edilememektedir. Türkiye'nin meyve ve sebze üretim miktarına göre ihracat miktarının çok düşük olmasının başlıca nedenleri; ihracata konu olan meyve ve sebze çeşitlerinin uluslararası piyasaların standartlarına uygun olmayışı, üretimden tüketime devam eden süreç içerisinde miktar ve kalite kayıplarının oldukça yüksek olması ve üreticilerden kaynaklanan sorunlar olarak gösterilebilir. Bu veya buna benzer nedenlerden dolayı Türkiye'nin toplam meyve ve sebze üretimin yaklaşık \% 5 'i ihraç edilebilmekte olup geri kalan \%95'lik kısım iç piyasalarda tüketilmektedir (AKİB, 2015). Bu bağlamda Türkiye'nin ihracatında önemli bir gelir kalemi oluşturabilecek potansiyele sahip olan bu sektörünün ihracat performansının araştırılması gerekmektedir. Bu nedenle çalışmada Türkiye'nin meyve ve sebze ihracatını etkileyen faktörler çekim modeli ile tahmini yapılmıştır.

Çalışmanın literatüre bir kaç noktada katkı sağlaması beklenilmektedir. Birincisi, meyve ve sebze ihracatının ele alındığı çalışma sayısı oldukça sınırlıdır. İkincisi, Türkiye’nin tarım ürünleri ihracatı ile ilgili çalışmalar da dahil olmak üzere veri seti açısından en geniş panel veri seti ile tahmin yapılmış olmasıdır. Üçüncüsü, önceki yapılan çalışmalardan farklı olarak bağımlı değişkenin nicel olarak düşük rakamlara sahip olması nedeniyle ortaya çıkabilecek sorunlarda tutarlı tahminler yapan ve çekim modellerinin logaritmik formundan kaynaklı değişen varyansı dikkate alan gelişmiş bir yaklaşım olan PPML kullanılmasıdır. Dördüncüsü, küresel ekonomik ve siyasi konjonktür dikkate alınarak oluşturulan kukla değişkenlerin kullanılmasıdır.

Türkiye'nin 63 ülkeye (Ek.1) yaptığı meyve ve sebze ihracatına ait verilerin ekonometrik olarak test edildiği bu çalışma bundan sonra şu sıra ile devam etmektedir. Çalışmanın ikinci bölümünde daha önce yapıllmış çalışmalara ilişkin 
literatür özeti sunulmaktadır. Üçüncü bölümünde tahmin edilen model ve veri seti tanıtılmıştır. Çalışmanın dördüncü bölümünde model tahminin kullanılan yöntem ele alınırken, beşinci bölümde analiz sonuçlarına yer verilmiş olup genel bir değerlendirme sonlandırılmıştır.

\section{Literatür Özeti}

Meyve ve sebze ihracatını etkileyen faktörlerin araştırıldığı çalışmalar literatürde sınırlı sayıda bulunmakla birlikte tarım ihracatını etkileyen faktörlerin meyve ve sebze ihracatını da etkilediği kabul edilmektedir. Türkiye üzerine yapılan sınırlı sayıda çalışmalardan Buguk, Isik, Dellal ve Allen (2003) döviz kuru ve döviz kuru dalgalanmaları kuru incir ve üzüm ihracatını negatif yönde etkilediğini tespit etmiştir. Atıcı ve Güloğlu (2006) çekim (Gravity) modelinin kullanıldığı çalışmada, Türkiye'nin meyve ve sebze ihracatını AB ülkelerinin gelirleri, Türk nüfus yoğunluğu ve Akdeniz ülkesi olma kukla değişkenleri pozitif yönde etkilerken, iki ülke arasındaki uzaklık negatif yönde etkilemiştir. AB ülkelerindeki nüfus değişkeni ise istatistiki yönden anlamsızdır. Nowak-Lehmann, Herzer, Martinez-Zarzoso ve Vollmer (2007) çalışmalarında Türkiye'nin Avrupa Birliği (AB)'ne yaptığı ihracatı sektörel olarak incelemiştir. Çekim modelinin kullanıldığı çalışmada tarım ürünlerinin (yenilebilir sebze, yenilebilir meyve ve fındık, hazır meyve, sebze ve findık ) ihracatında döviz kurunun pozitif etkisi olduğunun, Türkiye'nin AB'e üyelik sürecinin ve Ortak Tarım Politikası'na adaptasyonunun ihracatı artırdığını ileri sürmüştür.

Türkiye üzerine yapılan ve tarım sektörünün bir bütün olarak ele alan Demirel ve Erdem (2004) çalışmalarında reel döviz kuru ve reel döviz kuru belirsizliğinin Türkiye'nin ABD, Almanya, İngiltere, Fransa ve İtalya ülkelerine sektörel ihracatları üzerinde etkileri araştırmıştır. Çalışmada yer alan ülkelerin tamamı için olmasa da özellikle tarım sektörü için reel döviz kuru belirsizliğinin ihracat üzerinde negatif bir etkiye sahip olduğunu tespit etmiştir. Fidan (2006) ise reel döviz kurundan tarım ihracatına doğru tek yönlü bir nedenselliğin olduğu ve reel döviz kurundaki bir birimlik şokun ilk beş yılda tarım ihracatını pozitif yönde etkilediği ve reel döviz kurunun ihracata etkisi kısa dönemde uzun döneme göre daha küçük çapta olduğunu da tespit etmiştir. Erdem ve Nazlioglu (2008), Türkiye'nin AB ülkelerine tarım ürünleri ihracatını etkileyen faktörleri araştırdıkları çalışmada Atici ve Guloglu'nun çalışmalarında kullandıkları değişkenlere tarım arazilerinin kapladığı alan değişkenini de ekleyerek çekim modelini yeniden tahmin etmiştir. Erdem ve Nazlioglu, Atici ve Güloğlu'nun çalışmalarından farklı olarak $A B$ ülkelerinin nüfusu tarım ürünleri ihracatını pozitif yönde etkilerken, $A B$ ülkelerinin tarım arazilerinin kapladığı alan tarım ürünleri ihracatını negatif yönde etkilediğini tespit etmiştir.

Diğer ülkeler üzerine yapılan çalışmalar incelendiğinde; Sheldon, Mishraa, Pick ve Thompson (2013) döviz kuru oynaklığı ABD'nin hem meyve hem de sebze ihracatını negatif yönde etkilemektedir. Cho, Sheldon, ve McCorriston (2002), 10 gelişmiş ülkede döviz kuru belirsizliğinin sektörel bazda diş ticareti nasıl etkilediğini incelemiştir. Çekim modelinin kullanıldığı çalışmada ülke gelirleri tarım ürünleri dış ticaretini pozitif ama istatistiki olarak anlamsız yönde etkilerken, ülke nüfusları ve döviz kuru belirsizliği tarım ürünleri dış ticaretini negatif yönde ve istatistiki olarak anlamlı bir şekilde etkilemektedir. Ayrıca diğer sektörlere göre karşılaştırılma yapıldığında döviz kuru belirsizliği daha yüksek oranda tarım ürünleri ticaretini negatif yönde etkilemektedir. Cho, Sheldon, ve McCorriston (2002)'in çalışmasında kullandığı modeli kullanan Kandilov (2008), çalışmanın örneklemini genişleterek modeli tekrardan test etmiştir. Yapılan analiz sonucunda, döviz kuru dalgalanmalarının tarımsal ticarete etkisi, döviz kuru dalgalanmalarının toplam ticarete etkisine göre neredeyse önemsiz olduğunu tespit etmiştir. Kandilov, bu durumu tarımsal politikalar nedeniyle olabileceği şeklinde yorumlamıştır.

Fogarasi (2008) Romanya'nın tarım dış ticareti yaptı̆̆ı 54 ülkeye ait verileri çekim modeli kullanarak analiz etmiştir. Çalışmada ülke gelirleri ve nüfusları, iki ülke arasındaki uzaklıkları, döviz kuru oynaklığı ve kukla değişkenlerin (ortak dil, ortak sınır, gümrük birliklerine üyelikler vs.) tarım ürünleri ticaretine olan etkisi araştırılmıştır. Yapılan analiz sonucunda döviz kuru oynaklığı tarım ürünleri ihracatı üzerinde olumsuz etkisi olduğu, dış ülkelerin gelirleri ve nüfuslarının tarım ürünleri ihracatını olumlu yönde etkilediğini tespit etmiştir. Çalışmada sadece uzaklık değişkeni negatif yönde tarım ürünleri ihracatı etkilerken, kullanılan kukla değişkenlerin anlamsız oldukları tespit edilmiştir. Çekim modelinin kullanıldığı bir başka çalışmada ise Hatab, Romstad ve Huo (2010), Mısır'ın 50 ülkeye yaptığı tarım ürünleri ihracatını belirleyen faktörleri araştırmışlardır. Yapılan sabit etkili, tesadüfi etkili ve havuzlamış panel veri analizlerinde sadece Mısır'ın milli geliri ve kişi başına düşen geliri her üç panel veri analizde anlamlı sonuçlar verirken, Mısır'ın ve diğer ülkelerin dışa açıklıkları her üç panel veri analizde anlamsız sonuçlar vermiştir. Döviz kuru tarım ürünleri ihracatına etkisi ise sadece sabit etkili panel veri analizinde anlamlı sonuç verirken, katsayısı pozitif işaretlidir. Diğer ülkelerin milli gelirleri, hem havuzlanmış hem de tesadüfü etkili panel veri analizinde anlamlı sonuçlar vermiştir. Ayrıca, kullanılan kukla değişkenleri de anlamlı sonuçlar vermiştir.

Söz konusu çalışmalar dikkate alındığında, genel olarak panel ve zaman serisi analizleriyle meyve ve sebze/tarım ürünleri ihracatına etki eden faktörlerin farklı boyutlarının irdelendiği ifade edilebilir. Literatür taramasında meyve ve sebze ihracatı üzerine sınırlı sayıda çalışmaların olduğu belirlenmiştir. Yeni çalışmalar ile bu açıklığın kapatılacağı düşünülmektedir. 


\section{Panel Çekim Modeli ve Veri Seti}

Yapılan literatür taramasında, çekim modelinin sıkça kullanıldı̆̆ı görülmektedir. Ülkelerarası ticaret akımlarını açıklamakta kullanılan bu önemli model Tinbergen (1962), Poyhonen, (1963) ve Linnemann (1966)'ın çalışmalarıyla literatüre kazandırılmıştır. Çekim modelinin teorik altyapısı Anderson (1979), Bergstrand (1985), Helpman (1987), Wei (1996), Breuss ve Egger (1999), Egger (2000), Soloaga ve Winters (2001) ve Anderson ve Wincoop (2003) çalışmalarıyla oluşturulmuştur. Model tahmininde kullanılacak yöntemler ile ilgili katkılar ise Silva ve Tenreyro (2006), Martin ve Pham, (2008) Westerlund ve Wilhelmsson, (2011), Egger, Staub, Larch, ve Winkelmann (2011), Silva ve Tenreyro (2011) ve Baltagi, Egger ve Pfaffermayr (2014) çalışmaları ile sağlanmıştır.

Çekim modeline göre iki ülke arasındaki ticaret hacmi, ülkelerin büyüklükleri ile doğru orantılı, aralarındaki uzaklık ile ters orantılıdır. Bu ilişki meyve ve sebze ihracatı için Model (1)’ de ele alınmıştır.

$$
F_{i j t}=\beta_{0} \frac{\left(G D P_{i t}\right) *(G D P}{\left.D_{j t}\right)} \varepsilon_{i j t}
$$

Model (1)'de, $\mathrm{F}_{\mathrm{ijt}}$ Türkiye'nin meyve ve sebze ihracatını, $\beta_{0}$ sabit terimi ifade ederken ülkelerin ekonomik büyüklüklerini ifade etmek için Gayri Safi Yurtiçi Hasıla (GSYİH) kullanılmıştır. GDP i, ihracatçı ülkenin GSYİH’sini, $G P_{j}$ ithalatçı ülkenin GSYİH’sini ve Dist iki ülke arasındaki mesafeyi ifade etmektedir. Ayrıca kişi başına GSYİH (Inc) değişkeni de ekonomik büyüklüğü ifade etmekte için modele eklenmiş ve modelin yeni hali aşağıdaki gibidir ${ }^{1}$.

$F_{i j t}=\beta_{0} \frac{\left(G D P_{i}\right) *\left(G D P_{j}\right) *\left(I n c_{i}\right) *\left(I n c_{j}\right)}{\text { Dist }_{i j}} \varepsilon_{i j t}$

Model (2), aynı ülkelere ait veriler yeniden düzenlendiğinde aşağıda ki gibi olacaktır.

$F_{i j t}=\beta_{0} \frac{\left(G D P_{i t}\right) *\left(I n c_{i t}\right) *\left(G D P_{j t}\right) *\left(I n c_{j} t\right)}{D i s t_{i j}} \varepsilon_{i j t}$

$\left(G D P_{i}\right) *\left(I n c_{i}\right)$ değişkenleri ticaret yapılan ülkeden diğer ülkelere göre değişmediği için bu değişkenlerin ülkelerarası ticaret hacmini açıklama gücü yoktur. Bu nedenle modelden çıkartılmıştır (Bos ve Laar, 2004; Saray ve Karagöz, 2010). Elde edilen çekim modeline (3 nolu model ) her iki ülke arasındaki dış ticareti etkileyebileceği düşünülen faktörler eklenmiştir. Son olarak logaritması alınan ve gerekli düzenlemelerin yapıldığı model aşağıdaki gibidir.

$\log F_{i j t}=\log \beta_{0}+\alpha_{1} \log G D P_{j t}+\alpha_{2} \log I n c_{j t}-\alpha_{3} \log \operatorname{Dist}_{i j}+\theta_{i} \sum_{i=1}^{4} D+\log _{i j t}$

$\varepsilon_{\mathrm{ijt}}=\mu_{\mathrm{ij}}+\lambda_{\mathrm{t}}+\mathrm{v}_{\mathrm{ijt}}$

Modelde, $\varepsilon_{\mathrm{ijt}}$; hata terimini, $\mu_{\mathrm{ij}}$; gözlemlenmeyen birim etkilerini, $\lambda_{\mathrm{t}}$; gözlemlenemeyen zaman etkilerini, $\mathrm{v}_{\mathrm{ijt}}$; stokastik hata terimi, i Türkiye'yi, j diğer ülkeleri (1,2..63), ve t zaman dönemi (2004-2014) ifade etmektedir. Kukla değişkenler ise $\mathrm{D}_{1 \mathrm{j}}$ (Sinır Komşusu Ülke ise 1, değilse 0), $\mathrm{D}_{2 \mathrm{j}}$ (AB Üyesi Ülke ise 1, değilse 0), $\mathrm{D}_{3 \mathrm{jt}}$ (2008 Finansal Krizi 1, değilse 0) ve $\mathrm{D}_{4 \mathrm{j}}$ (Arap Baharı Krizi 1, değilse 0) ifade etmektedir.

Çalışmada, ihracata ilişkin veriler, Türkiye İhracatçılar Meclisi veri tabanından milyon US\$ olarak alınmış, Merkez Bankası Döviz Kuru Alış Fiyatı (TL/US\$) ile TL' ye dönüştürülmüştür. 2003 yılı baz alınan Tüketici Fiyat Endeksi kullanılarak ihracat verileri milyon TL cinsinden reel hale getirilmiş ve logaritmik formda kullanılmıştır. Ekonomik büyüklük göstergesi olarak kullanılan GSYİH ve kişi başına GSYİH verileri Dünya Bankası'nın veri tabanından alınmıştır. GSYİH serileri 2005 yılı sabit fiyatları ile dolar cinsinden hesaplanmaktadır. Ülkelerarası uzaklık için, ülkelerin başkentleri arası uzaklık km cinsen hesaplanmış olup, (http://www.distancefromto.net/) web adresinden alınmıştır.

\section{Yöntem}

Panel veri analizi, yatay kesit ve zaman serisi verilerinin birleştirilmesi ile oluşan panel verilerin tahmin edilmesi yöntemidir. Panel veri analizlerinde klasik model, sabit etki model ya da tesadüfi etkili modellerinden hangisinin kullanılması gerektiğine karar verilmesi gerekmektedir. Bu amaçla ya literatürdeki önsel kabuller ya da model belirleme test istatistikleri kullanılmaktadır. Zamana göre değişmeyen (ülkelerarası uzaklık, kukla değişken gibi vs.) değişkenlerin var olduğu modellerde Tesadüfi etkili modellerin yapılması tercih edilmektedir (Atici ve Guloglu, 2006). Uygulamalı çalışmalarda panel çekim modeli doğrusal hale getirilerek En Küçük Kareler (OLS) tekniğini kullanan tahmincilerle model tahmini yapılmaktadır. OLS yönteminin kullanılmasından dolayı model tahmininde hata varyansının sabit olduğu varsayılmaktadır. Ancak, Silva ve Tenreyro (2006) standart çekim modeli, doğrusal hale getirildiğinde hata terimin sabit varyans varsayımını ihlal ettiğini Monte Carlo denemeleriyle tespit etmiştir. Westerlund ve Wilhelmsson (2011) ise özellikle panel verilerin kullanıldığı çalışmalarda logaritmik dönüşümün yapıldığında daha büyük sorunlara yol açtığını ifade etmiştir. Aslında değişen varyans sorununun ortaya çıkmasında Jensen eşitsizliği (Jensen's inequality) sorunsalı yatmaktadır. Söz konusu sorun aşağıdaki modeller ile açıklanmaktadır (Herrera ve Baleix, 2012).

$\log F_{i j t}=\log \beta_{0}+\alpha_{1} \log G D P_{j}+\alpha_{2} \log I n c_{j}-\alpha_{3} \log D i s t_{i j}+\log \varepsilon_{i j t}$

Model (6), beklenen değerleri formunda ele alındığında Model (7) ve daha sonra Model (8) elde edilmektedir.

$E\left[\log F_{i j t}\right]=E\left[\log \beta_{0}+\alpha_{1} \log G D P_{j}+\alpha_{2} \log I n c_{j}-\alpha_{3} \log D i s t_{i j}+\log \varepsilon_{i j t}\right]$

\footnotetext{
${ }^{1}$ Çekim modeli çalışmalarında nüfus değişkeni ekonomik büyüklüğü ifade etmek için kullanılmaktadır. Kişi başına düşen gelir yerine nüfus değişkeni modele eklenerek tahmin edildiğinde, nüfus değişkenin katsayısının negatif olduğu gözlemlenmiştir. Bu duruma göre nüfusça kalabalık ülkelerin genellikle yoksul ve/veya düşük gelir gurubunda olmaları neden olmuştur. Çünkü, veri seti nüfusu yirmi milyondan fazla olan ve olmayanlar diye iki gruba ayrılarak tahminler yapılmış ve bu sonuç tespit edilmiştir. Ayrıca, meyve ve sebzeye olan talebi etkilemede kişi başına düşen gelir teorik olarak nüfusa göre daha önemli bir faktördür. Bu nedenle çalışmada kişi başına düşen gelir değişkeninin kullanılması uygun görülmüştür.
} 
$E\left[\log F_{i j t}\right]=E\left[\log \beta_{0}\right]+\alpha_{1} E\left[\log G D P_{j}\right]+\alpha_{2} E\left[\log I n c_{j}\right]-\alpha_{3} E\left[\log D i s t_{i j}\right]+E\left[\log \varepsilon_{i j t}\right]$

Beklenen değerleri; $\log E\left[\varepsilon_{i j t}\right] \neq E\left[\log \varepsilon_{i j t}\right]$, eşit olamayacağından sabit varyans varsayımı ihlal edilecektir ${ }^{2}$. Söz konusu durumda model OLS yerine Doğrusal Olmayan En Küçük Kareler (NLS) ya da PPML ile tahmin edilebilmektedir. Ancak PPML, küçük örneklemlerde NLS'ye göre daha etkindir (Silva ve Tenreyro, 2006) ${ }^{3}$. Bu nedenle analizde PPML tercih edilmiştir. PPML'nin tercih edilmesinin bir başka neden ise bağımlı değişkenin bazı yıllarda sıfır olması ve bazı yıllarda ise oldukça küçük değerler almasıdır. PPML tahmincisinde, poisson regresyonu aşağıdaki gibi elde edilmektedir. Ülkelerarası ticaretin beklenen değeri $E\left[F_{i} \mid x\right]=\exp \left(x_{i} \beta\right)$ olmak üzeri;

$\sum_{i=1}^{n}\left[F_{i}-\exp \left(x_{i} \breve{\beta}\right)\right] \exp \left(-x_{i} \breve{\beta}\right) x_{i}=0$

şeklinde birinci sıra koşuluyla hesaplanmaktadır. Modelde, $F_{i}$ bağımlı değişkeni ifade ederken, $x_{i}$, bağımsız değişkenleri ifade etmektedir.

\section{Bulgular}

PPML yöntemi ile altı farklı regresyon tahmini gerçekleştirilmiştir. Kurulan tüm regresyonlarda değişkenlerin istatistiksel olarak anlamlı oldukları gözlemlenmiştir. Model logaritmik formda olduğu için katsayılar esneklikleri vermektedir. Değişkenlerin kat sayıları incelendiğinde esnekliklerinin düşük oldukları tespit edilmiştir. Bu sonuç iktisat literatürü ile uyumludur. Yapılan PPML tahmin sonuçları Tablo 1' de verilmiştir.

Tablo 1: PPML Tahmin Sonuçları

\begin{tabular}{lllllll}
\hline Değişkenler & I & II & III & IV & V & VI \\
\hline $\mathrm{B}_{\mathrm{o}}$ & $2.355738^{*}$ & $2.178283^{*}$ & $2.394467^{*}$ & $2.345593^{*}$ & $2.318284^{*}$ & $2.190518^{*}$ \\
$\mathrm{GDP}$ & $.0590341^{*}$ & $.0568506^{*}$ & $.0598448^{*}$ & $.0582713^{*}$ & $.0586541^{*}$ & $.056697^{*}$ \\
$\mathrm{Inc}$ & $.0264924^{*}$ & $.0337444^{*}$ & $.0324795^{*}$ & $.0269286^{*}$ & $.0281389^{*}$ & $.0390401^{*}$ \\
Dist & $-.0801965^{*}$ & $-.0643441^{*}$ & $-.0912743^{*}$ & $-.0798262^{*}$ & $-.0773492^{*}$ & $-.071803^{*}$ \\
$\mathrm{D}_{1}$ & & $.120944^{*}$ & & & & $.1147199^{*}$ \\
$\mathrm{D}_{2}$ & & & $-.0415056^{*}$ & & & $-.030850^{*}$ \\
$\mathrm{D}_{3}$ & & & & $-.0224923^{*}$ & & $-.018703^{*}$ \\
$\mathrm{D}_{4}$ & & & & & $-.0680049^{*}$ & $-.031947^{*}$ \\
\hline $\mathrm{R}^{2}$ & 0.62 & 0.65 & 0.63 & 0.62 & 0.63 & 0.66 \\
$\mathrm{~N}$ & 693 & 693 & 693 & 693 & 693 & 693 \\
\hline
\end{tabular}

Not: *, \%1 de anlamlllık düzeyini ifade etmektedir.

Çekim modelinin tahmin sonuçlarına göre Türkiye'nin meyve ve sebze ihracatı, ihracat yaptığı ülkelerin ekonomik büyüklüğünden ve kişi başına düşen gelirden pozitif, aradaki uzaklıktan ise negatif yönde etkilenmektedir. Modele, Türkiye'nin sınır komşularını ifade eden D1 kukla değişkeni eklenildiğinde, meyve ve sebze ihracatını pozitif yönde etkilemektedir. Yani, meyve ve sebze ihracatı açısından sınır komşuluk ilişkisi önemli bir faktördür. Modele, AB üye ülkelerini ifade eden D2 kukla değişkeni eklenildiğinde ise, meyve ve sebze ihracatını negatif yönde etkilemektedir. Bu durum, Türkiye ve $\mathrm{AB}$ üye ülkeleri arasındaki meyve ve sebze ihracatında açık bir rekabet olduğunu göstermektedir. Modele, 2008 finansal krizini ifade eden D3 kukla değişkenini eklediğimizde, meyve ve sebze ihracatını negatif yönde etkilediği görülmektedir. Benzer şekilde model Arap Baharı olarak bilenen ve bazı Arap ülkelerindeki siyasi ve ekonomik krizi ifade eden D4 kukla değişkeni eklenildiğin de benzer sonuçlar elde edilmektedir. Son olarak tüm değişkenleri içeren model tahmin edildiğinde ise bireysel olarak yapılan tahminlerle benzerlik gösterdiği tespit edilmektedir.

\section{Sonuç ve Değerlendirme}

Bu çalışmada Türkiye'nin meyve ve sebze ihracatını etkileyen faktörler çekim modeli ile araştırılmıştır. Yapılan literatür taramasında en uygun modelin çekim modeli olduğu tespit edilmiştir. Bu amaçla, çalışmada 63 ülkeye ait ve 2004-2014 dönemini kapsayan yıllık panel veriler çekim modelinde kullanılmıştır. Model tahmininde ise klasik tahmincilerin yerine PPML tahmincisi kullanılarak değişen varyans kaynaklı sorunların önüne geçilmiştir.

Yapılan analiz sonucuna göre Türkiye'nin meyve ve sebze ihracatı yapılan ülkenin ekonomik büyüklüğünden ve kişi başına düşen gelirinden pozitif yönde, aralarındaki uzaklıktan ise negatif yönde etkilenmektedir. Kukla değişkenler modele eklenildiğinde; $\mathrm{AB}$ üyesi ülke olma kukla değişkeni meyve ve sebze ihracatı negatif yönde etkilerken, sınır komşusu ülke olma kukla değişkeni ise meyve ve sebze ihracatını pozitif yönde etkilenmektedir. Ayrıca Türkiye, 2008 finansal krizi ve 2010 Arap Baharı krizinden olumsuz yönde etkilenerek meyve ve sebze ihracatı azalmaktadır.

\footnotetext{
${ }^{2}$ Değişen varyans durumunda parametrelerin katsayı tahminleri değişmese de, tahminler tutarsız olacaktır.

${ }^{3}$ NLS ile model tahmininde küçük örneklemlerde noisier observations (gürültü gözlemleri)'e daha fazla ağırlık vermektedir. Bu nedenle PPML küçük örneklemlerde daha etkindir. Ayrıntılı bilgi için bakınız, Westerlund ve Wilhelmsson, 2011.
} 
Araştırmanın sonuçlarından hareketle, Türkiye meyve ve sebze ihracatında ekonomik büyüklüğü ve kişi başına düşen geliri yüksek olan ülkeleri tercih etmesinin gerektiği söylenebilir. Bu tercih söz konusu olduğunda ise uzaklık önemli bir faktördür. Çünkü, uzaklık işlem maliyeti, taşıma maliyeti, teslim süresi (meyve ve sebzelerin dayanıklıkları), kültürel farklılıklar vs. gibi nedenlerden dolayı mesafe arttıkça meyve ve sebze ihracatı azalmaktadır. Bu durumda, bulunduğu coğrafya konum gereğince ekonomik büyüklüğü, kişi başına düşen geliri ve yakınlığı açısından AB ülkeleri tercih edilmelidir. Ancak, AB içerisinde benzer ürünleri üreten (özellikle Yunanistan, İtalya ve İspanya) ülkeler ile rekabet etme söz konusudur. Böyle bir durumda rekabet koşulları en azından benzer olmalı (ürün destekleri, marka algısı vs.) ya da ürün çeşitliğine gidilmelidir. AB üye ülkeleri dışında alternatif ise sınır komşuları ile iyi ilişkiler geliştirilmesidir. Ancak, siyasi konjonktür gereği başta Irak ve Suriye olmak üzere bir dizi ekonomik ve siyasi sorunlar yaşayan İran, Gürcistan ve Ermenistan gibi ülkelerle sınır komşusu olunması nedeniyle kısa dönemde uygun koşulların oluşması beklenilmemektedir. Bu kapsamda analiz sonuçları değerlendirildiğinde, Türkiye'nin meyve ve sebze ihracat politikasını şekillendirirken politika yapıcıları tespit edilen faktörleri dikkate almalarında fayda vardır. 


\section{KAYNAKÇA}

AKİB. (2015). Akdeniz İhracatçı Birlikleri, Türkiye Geneli Yaş Meyve Sebze Değerlendirme Raporları, Erişim Tarihi:14.08.2015.http://www.akib.org.tr/tr/ihracat-arastirma-raporlari-yas-meyve-sebze-ihracatcilaribirligi.html

Anderson, J.E. (1979). Error Components and Seemingly Unrelated Regressions. Econometrica, 45 (1):199-209.

Anderson, J. E. ve Wincoop, E. (2003). Gravity with Gravitas: A Solution to the Border Puzzle. American Economic Review, 93: 170-192.

Atici, C. ve Guloglu, B. (2006). Gravity Model of Turkey's Fresh and Processed Fruit and Vegetable Export to the EU. Journal of International Food \& Agribusiness Marketing, 18:3-4, 7-21.

Baltagi, H. B., Egger, P. ve Pfaffermayr, M. (2014). Panel Data Gravity Models of International Trade. CESifo Working Paper, No. 4616.

Bergstrand, J.H. (1985). The Gravity Equation in International Trade: Some Microeconomic Foundations and Empirical Evidence. The Review of Economics and Statistics, 67: 474-481.

Bos, J.W.B. ve M. van de Laar. (2004). "Explaining Foreign Direct Investment in Central and Eastern Europe: An Extended Gravity Approach". Netherlands Central Bank, DNB Working Papers, No: 008.

Breuss, F. ve Egger, P. (1999). How Reliable are Estimations of East-West Trade Potentials Based on Cross-Section Gravity Analyses?. Empirica , 26 (2): 81-95.

Buguk, C., M. Isik, I. Polat, ve A. Allen. (2003). The Impact of Exchange Rate Variability on Agricultural Exports of Developing Countries: The Case of Turkey. Journal of International Food and Agribusiness Marketing, 13: 83105.

Cho, G., Sheldon, I. ve McCorriston S. (2002). Exchange Rate Uncertainty and Agricultural Trade. American Journal of Agricultural Economics, 84(4): 931-942.

Demirel, B. ve. Erdem, C. (2004). Döviz Kurlarındaki Dalgalanmaların İhracata Etkileri: Türkiye Örneği. İktisat, İşletme ve Finans Dergisi, 19 (223): 116-127.

Egger, P. (2000). A Note on the Proper Econometric Specification of the Gravity Equation. Economics Letters, 66: 2531.

Egger, P., Larch, M., Staub, K. E. ve Winkelmann, R. (2010). The Trade Effects of Endogenous Preferential Trade Agreements. Working Paper, Socioeconomic Institute, University of Zurich, 1013.

Erdem, E. ve Nazlioglu, S. (2008). Gravity Model of Turkish Agricultural Exports to the European Union. International Trade and Finance Association Working Papers, 21.

Fidan, H. (2006). Impact of the Real Effective Exchange Rate (Reer) on Turkish Agricultural Trade. International Journal of Human and Social Sciences, 1(2): 70-82.

Fogarasi, J. (2008). The Effect of Exchange Rate Volatility upon ForeignTrade of Romanian Agricultural Products. Cerge-Ei Working Paper, 1-16.

Hatab, A.A., Romstad, E. ve Huo, X. (2010) "Determinants of Egyptian Agricultural Exports: A Gravity Model Approach" Modern Economy, 1:134-143.

Helpman, E. (1987) "Imperfect Competition and International Trade: Evidence from Fourteen Industrial Countries" Journal of the Japanese and International Economies, 1, 62-81.

Herrera, E. G. ve Baleix, J. M. (2012). EMU Impact of on Third countries' Exports. A Gravity Approach. The Working Papers, Department of Economic Theory and Economic History of the University of Granada, 10/26.

Kandilov T, I. (2008). The Effects of Exchange Rate Volatility on Agricultural Trade. American Journal of Agricultural Economics, 90(4): 1028- 1043.

Linnemann, H. (1966). An Econometric Study of International Trade Flows. Amsterdam, North Holland Press.

Martin, W. ve Pham, S.C. (2008). Estimating the Gravity Equation when Zero Trade Flows are Frequent. MPRA Working Paper, 9453.

Nowak-Lehmann F, Herzer D, Martinez-Zarzoso, I. ve Vollmer. S. (2007). The Impact of a Customs Union Between Turkey and the EU on Turkey's Exports to the EU. JCMS. J Common Market S, 45(3): 719-743.

Poyhonen, P. (1963). A Tentative Model for the Volume of Trade between Countries. Weltwirtschaftliches Archiv, 90, 93-99.

Saray, M.O. ve Karagöz, K. (2010). "Gravitational Determinants of Tourist Inflows in Turkey”. Zonguldak Karaelmas Üniversitesi Sosyal Bilimler Dergisi, 6 (11): 29 - 40.

Sever, E. (2012). Döviz Kuru Dalgalanmalarının Tarımsal Dış Ticarete Etkisi: Türkiye Örneği. Akademik Araştırmalar ve Çalışmalar Dergisi, 4(7): 17-35.

Sheldon, I. M. , Mishra, S. K. , Pick, D. ve Thompson, S. (2013). Exchange Rate Uncertainty and US Bilateral Fresh Fruit and Fresh Vegetable Trade: An Application of the Gravity Model. Applied Economics, 45(15): 2067-2082.

Silva, J. M. C. S. ve Tenreyro, S. (2006). The Log of Gravity. Review of Economics \& Statistics, 88(4): 641-658.

Silva, J. M. C. S. ve Tenreyro, S. (2011). Further Simulation Evidence on the Performance of The Poisson PseudoMaximum Likelihood Estimator. Economics Letters, 112(2): 220-222.

Soloaga, I. ve Winters, A. (2001). Regionalism in the Nineties: What Effects on Trade? The North American Journal of Economics and Finance, 12 (1): 1-29.

Tinbergen, J. (1962). Shaping the World Economy. New York, Twentieth Century. 
Kaplan, F. / Journal of Yasar University, 2016, 11/42, 77-83

Wei, S.-J. (1996). Intra-National Versus International Trade: How Stubborn are Nations in Global Integration?. NBER, Working Paper, 5531.

Westerlund, J. ve Wilhelmsson, F. (2011). Estimating the Gravity Model Without Gravity Using Panel Data. Applied Economics, 43(6): 641-649.

Ek 1 .

Tablo 2. Çalışmada Kullanılan Ülkeler

\begin{tabular}{|c|c|c|c|c|c|c|}
\hline Almanya & Bulgaristan & Gabon & İrlanda & Katar & Nijerya & Şili \\
\hline Avustralya & Cezayir & Gambiya & İspanya & Kostarika & Norveç & Tunus \\
\hline Avusturya & Çek Cumhuriyeti & Gana & İsrail & Letonya & Polonya & Uganda \\
\hline Bahreyn & $\begin{array}{l}\text { Çin Halk } \\
\text { Cumhuriyeti }\end{array}$ & $\begin{array}{l}\text { Güney Afrika } \\
\text { Cumhuriyeti }\end{array}$ & İsveç & Lübnan & Portekiz & Ukrayna \\
\hline Belçika & Danimarka & Gürcistan & İsviçre & Macaristan & Romanya & Umman \\
\hline $\begin{array}{l}\text { Birleşik Arap } \\
\text { Emirlikleri }\end{array}$ & Ekvator Ginesi & Hirvatistan & İtalya & Makedonya & $\begin{array}{l}\text { Rusya } \\
\text { Federasyonu }\end{array}$ & Uruguay \\
\hline Birleşik Devletler & Fildiși Sahili & Hollanda & Japonya & Malezya & Singapur & Venezüella \\
\hline Birleşik Krallık & Finlandiya & Irak & Kamerun & Malta & Slovakya & Yeni Zelanda \\
\hline Brezilya & Fransa & $\begin{array}{l}\text { İran (İslam } \\
\text { Cum.) }\end{array}$ & Kanada & Moldova & Suudi Arabistan & Yunanistan \\
\hline
\end{tabular}

